\title{
Pathophysiology of Post-Thrombotic Syndrome: The Effect of Recurrent Venous Thrombosis and Inherited Thrombophilia
}

\author{
Raghid Kreidy \\ Department of Vascular Surgery, Saint George Hospital, University Medical Center, University of Balamand, Youssef Sursock Street, \\ P.O. Box 166378, Achrafieh, Beirut 1100 2807, Lebanon \\ Correspondence should be addressed to Raghid Kreidy, docrkdy@inco.com.lb
}

Received 9 August 2011; Accepted 20 September 2011

Academic Editors: J. K. Raines and C. Zaragoza

Copyright (๑) 2011 Raghid Kreidy. This is an open access article distributed under the Creative Commons Attribution License, which permits unrestricted use, distribution, and reproduction in any medium, provided the original work is properly cited.

Post-thrombotic syndrome is an important chronic complication of deep vein thrombosis. This syndrome can be debilitating to patients and has a major economic impact on health care services. The pathophysiology of post-thrombotic syndrome is currently incompletely understood. Because therapeutic options for post-thrombotic syndrome are extremely limited and results are often disappointing, recognizing of the pathophysiology and risk factors of this syndrome is essential to prevent the disabling consequences of this disease. The present paper focuses on risk determinants of post-thrombotic syndrome after deep vein thrombosis. The contribution of recurrent venous thrombosis and inherited thrombophilia to the pathogenesis of this syndrome is reviewed and discussed in details.

\section{Introduction}

Venous thromboembolism (VTE) is currently the third most common disorder in western population following myocardial infarction and stroke [1]. It remains a serious healthcare problem for the community. Pulmonary embolism (PE) is the major early complication of deep venous thrombosis (DVT). With its attendant mortality, $\mathrm{PE}$ is the most devastating complication of acute DVT. PE accounts for 200000 deaths each year in the United States (US), and the annual cost of the treatment is measured in billions of dollars $[2,3]$.

Post-thrombotic syndrome is the most important longterm complication of DVT resulting from venous valvular damage and persistent luminal obstruction. Although less dramatic than $\mathrm{PE}$, post-thrombotic syndrome is responsible for the greater degree of chronic socioeconomic morbidity. As many as 29 to $79 \%$ of patients may have long term manifestation of pain, edema, hyperpigmentation, or ulceration after an episode of acute DVT [4-6]. Severe manifestations and ulceration occur in $4 \%$ to $6 \%$ and $7 \%$ to $23 \%$, respectively $[7,8]$. The prevalence of venous ulceration is at least 300 per 100000 and approximately $25 \%$ are due to DVT $[9,10]$. In the United States, skin changes and ulceration are present in 6 to 7 million and 400,000 to 500,000 people, respectively [11]. Estimates of the overall annual cost of chronic venous insufficiency vary from 720 millions to 1 billion US dollars in western European countries representing $1 \%$ to $2 \%$ of the total health care budget, to 3 billion US dollars in the US $[12,13]$. Appreciation of the factors involved in the development of post-thrombotic syndrome is important in its prevention and management. The purpose of this paper is to determine the factors that contribute to the constitution of this syndrome focusing essentially on the role of venous thrombosis recurrence and inherited thrombophilia.

\section{Discussion}

Post-thrombotic syndrome (PTS) is observed in $0.5 \%$ to $1 \%$ of the population with ulcer and in $3 \%$ to $5 \%$ without ulcer [14]. Pathophysiology of PTS is complex and not entirely understood. This syndrome is more commonly observed in male gender, obese, and elderly patients [15]. The influence of several risk factors on the incidence of PTS is till controversial [16]. The determinants of postthrombotic manifestations include the rate of recanalization, 
the global extend of reflux, the anatomic distribution of reflux and obstruction, the recurrent thrombotic events, and thrombophilia.

Ambulatory venous hypertension may result from either venous reflux or persistence venous obstruction. Although valvular incompetence appears to be clinically more important, severe post-thrombotic sequelae occur in patients having a combination of valvular incompetence and luminal venous obstruction rather than either abnormalities alone [17-19]. Despite its importance, valvular dysfunction is not universal after acute DVT, reflux developing in only $33 \%$ to $59 \%$ of involved venous segments [20]. Reflux occurs not only in segments involved by thrombus, but also in segments remote from them. Reflux develops and progresses over time not only in venous segment distal to the thrombotic location but also in segments proximal to the site of thrombosis. This mechanism is yet poorly understood [17, 21-23]. A plausible explanation, described by Raju et al., is that perivenous and mural fibrosis may extend beyond the thrombosed segment to involve adjacent segments of preserving valve cusps, but inducing secondary reflux from valve station restriction [24]. Long-term ultrasound follow-up studies of patients treated with anticoagulants have demonstrated that the time to complete recanalization was related to the ultimate development of reflux [25]. Depending upon the venous segment involved, complete recanalization required 2.3 to 7.3 times longer in segments developing reflux than in segments in which valve function was preserved [25].

Proximal DVT, the presence of multiple sites of DVT, and anatomically extensive DVT have been associated with an increased rate of PTS $[15,18,26-29]$. The development of this syndrome is also related to the global extend of reflux and to the anatomic distribution of reflux and obstruction. Involvement of calf veins in the presence of proximal vein thrombosis increases the likelihood of PTS [18]. Reflux in the distal deep venous segments, particularly the popliteal and posterior tibial veins, is most commonly associated with post-thrombotic skin changes [29-31]. With respect to venous obstruction, the severity of post-thrombotic manifestations is most significantly related to persistent popliteal thrombosis [32]. Superficial reflux is also critically important and has been reported in $84 \%$ to $94 \%$ of patients with chronic skin changes and $60 \%$ to $100 \%$ of patients with venous ulceration.

Recurrent thrombotic events are common and have a detrimental effect on valvular competence and on the development of PTS [33-35]. Assessment of clinical risk factors for venous thrombosis may provide useful prognostic information for recurrence. Recurrence rate is low in conjunction with a major reversible risk factor (3\% the first year and $10 \%$ over 5 years), intermediate in minor reversible risk factor (5\% in the first year and $15 \%$ over 5 years), and relatively high in idiopathic VTE and elderly patients $(10 \%$ in the first year and $30 \%$ over 5 years) [36-39]. Fifty to $70 \%$ of idiopathic DVT are due to inherited thrombophilia [40]. The risk of recurrence is higher among patients with permanent risk factors including inherited prothrombotic abnormalities than among patients who have suffered trauma or underwent surgery [32]. Factor V-Leiden, prothrombin G 20210 A mutation, and MTHFR mutation leading to hyperhomocysteinemia are the most commonly observed prothrombotic genetic abnormalities associated with venous recurrence [ 41 , 42]. Ipsilateral recurrence has been strongly associated with PTS $[28,33,39,43]$. Re-thrombosis of a partially occluded or recanalized segment further increases the risk of reflux [40]. Reflux has been noted to develop in $36 \%$ to $73 \%$ of segments with re-thrombosis, a very higher rate, comparing to segments without re-thrombosis [44]. Consistent with these observations, recurrent thrombotic events have been observed in $45 \%$ of patients with PTS in comparison to only $17 \%$ of asymptomatic subjects [45]. Prandoni et al. reported a six times greater risk of PTS among patients with recurrent thrombosis [7].

Thrombophilia is increasingly recognized as a risk factor for DVT, which in turn is a major risk factor for chronic venous insufficiency. However, available information concerning the relation between thrombophilia and PTS is limited and still controversial. While some authors failed to demonstrate any correlation between thrombophilia and PTS, others suggested a role of inherited thrombophilia and mainly factor V-Leiden mutation in the development of PTS and leg ulcers [46-48]. PTS is commonly reported among patients with proximal DVT. Thrombophilia, detected among $29 \%$ of patients with proximal DVT, is considered an independent predictor of persistent residual venous thrombosis which has been recognized as an important factor for recurrent venous thrombosis and PTS $[49,50]$. These data suggest that inherited thrombophilia contributes to the constitution of post-thrombotic syndrome.

\section{Conclusion}

PTS syndrome occurs more frequently when venous thrombosis is extensive or affects proximal veins, popliteal, and calf veins. Superficial veins involvement is also commonly associated with the development of PTS. Recurrence venous thrombosis has been strongly involved in the constitution of PTS. The risk of recurrent venous thrombotic events is higher among patients with idiopathic DVT and with permanent risk factors including inherited prothrombotic abnormalities. Thrombophilia seems to interfere in the development of PTS either directly by prolonging residual venous thrombosis or indirectly by increasing venous thrombotic recurrence rate. Further studies are required to elucidate the pathophysiology of PTS and to confirm the importance of recurrence rate and inherited thrombophilia in the pathogeneses of PTS.

\section{References}

[1] I. A. Naess, S. C. Christiansen, P. Romundstud et al., "Incidence and mortality of venous thrombosis," Journal of Thrombosis, vol. 5, no. 4, pp. 692-699, 2007.

[2] J. Avorn and W. C. Winkelmayer, "Comparing the costs, risks, and benefits of competing strategies for the primary prevention of venous thromboembolism," Circulation, vol. 110, supplement 1, pp. IV25-IV32, 2004. 
[3] R. D. Hull, G. F. Pineo, and G. E. Raskob, "The economic impact of treating deep vein thrombosis with low- molecularweight heparin: outcome of therapy and health economy aspects," Haemostasis, vol. 28, supplement 3, pp. 8-16, 1998.

[4] D. J. Lindner, J. M. Edwards, E. S. Phinney, L. M. Taylor, and J. M. Porter, "Long - term hemodynamic and clinical sequelae of lower extremity deep vein thrombosis," Journal of Vascular Surgery, vol. 4, no. 5, pp. 436-442, 1986.

[5] P. Prandoni, S. Villalta, P. Polistena, E. Bernardi, A. Cogo, and A. Girolami, "Symptomatic deep-vein thrombosis and the post-thrombotic syndrome," Haematologica, vol. 80, supplement 2, pp. 42-48, 1995.

[6] D. E. Strandness, Y. Langlois, M. Cramer, A. Randlett, and B. L. Thiele, "Long-term sequelae of acute venous thrombosis," Journal of the American Medical Association, vol. 250, no. 10, pp. 1289-1292, 1983.

[7] P. Prandoni, A. W. A. Lensing, A. Cogo et al., "The long-term clinical course of acute deep venous thrombosis," Annals of Internal Medicine, vol. 125, no. 1, pp. 1-7, 1996.

[8] M. Monreal, A. Martorell, J. M. Callejas et al., "Venographic assessment of deep vein thrombosis and risk of developing post-thrombotic syndrome: a prospective study," Journal of Internal Medicine, vol. 233, no. 3, pp. 233-238, 1993.

[9] O. Nelzen, D. Bergqvist, A. Lindhagen, and T. Hallbook, "Chronic leg ulcers: an underestimated problem in primary health care among elderly patients," Journal of Epidemiology and Community Health, vol. 45, no. 3, pp. 184-187, 1991.

[10] O. Nelzen, D. Bergqvist, and A. Lindhagen, "Leg ulcer etiology: a cross sectional population study," Journal of Vascular Surgery, vol. 14, no. 4, pp. 557-564, 1991.

[11] F. R. Rosendaal, "Venous thrombosis: a multicausal disease," The Lancet, vol. 353, no. 9159, pp. 1167-1173, 1999.

[12] C. V. Ruckley, "Socioeconomic impact of chronic venous insufficiency and leg ulcers," Angiology, vol. 48, no. 1, pp. 6769, 1997.

[13] M. McGuckin, R. Waterman, J. Brooks et al., "Validation of venous leg ulcer guidelines in the United States and United Kingdom," American Journal of Surgery, vol. 183, no. 2, pp. 132-137, 2002.

[14] R. Eichlisberger, M. T. Widmer, B. Frauchiger, L. K. Widmer, and K. Jager, "On the incidence of the post-thrombotic syndrome," Wiener Medizinische Wochenschrift, vol. 144, no. 10-11, pp. 192-195, 1994.

[15] S. R. Kahn, "The post-thrombotic syndrome," Hematology/ American Society of Hematology Education Program, vol. 2010, pp. 216-220, 2010.

[16] S. Reich-Schupke, P. Altmeyer, and M. Stucker, "What do we know about post-thrombotic syndrome? Current status of post-thrombotic syndrome in adults," Journal der Deutschen Dermatologischen Gesellschaft, vol. 8, no. 2, pp. 81-87, 2010.

[17] B. F. Johnson, R. A. Manzo, R. O. Bergelin, and D. E. Strandness, "Relationship betweenchanges in the deep venous system and the development of the post-thromboticsyndrome after an acute episode of lower limb deep vein thrombosis. A one- to six-year follow- up," Journal of Vascular Surgery, vol. 21, no. 2, pp. 307-313, 1995.

[18] N. Labropoulos, T. Waggoner, W. Sammis, S. Samali, and P. J. Pappas, "The effect of venous thrombus location and extent on the development of post-thrombotic signs and symptoms," Journal of Vascular Surgery, vol. 48, no. 2, pp. 407-412, 2008.

[19] S. Vedantham, "Valvular dysfunction and venous obstruction in the post-thrombotic syndrome," Thrombosis Research, vol. 123, no. 4, pp. S62-S65, 2009.
[20] M. H. Meissner, T. W. Wakefield, E. Ascher et al., "Acute venous disease: venous thrombosis and venous trauma," Journal of Vascular Surgery, vol. 46, supplement 6, pp. S25-S53, 2007.

[21] M. T. Caps, R. A. Manzo, R. O. Bergelin, M. H. Meissner, and D. E. Strandness Jr., "Venous valvular reflux in veins not involved at the time of acute deep vein thrombosis," Journal of Vascular Surgery, vol. 22, no. 5, pp. 524-531, 1995.

[22] A. Markel, R. A. Manzo, R. O. Bergelin, and D. E. Strandness Jr., "Valvular reflux after deep vein thrombosis: incidence and time of occurrence," Journal of Vascular Surgery, vol. 15, no. 2, pp. 377-384, 1992.

[23] L. A. Killewich, G. R. Bedford, K. W. Beach, and D. E. Strandness Jr., "Spontaneous lysis of deep venous thrombi: rate and outcome," Journal of Vascular Surgery, vol. 9, no. 1, pp. 89-97, 1989.

[24] S. Raju, R. K. Fredericks, C. A. Hudson, T. Fountain, P. N. Neglen, and M. Devidas, "Venous valve station changes in "primary" and post-thrombotic reflux: an analysis of 149 cases," Annals of Vascular Surgery, vol. 14, no. 3, pp. 193-199, 2000.

[25] M. H. Meissner, R. A. Manzo, R. O. Bergelin, A. Markel, and D. E. Strandness, "Deep venous insufficiency: the relationship between lysis and subsequent reflux," Journal of Vascular Surgery, vol. 18, no. 4, pp. 596-608, 1993.

[26] S. Ziegler, M. Schillinger, T. H. Maca, and E. Minar, "Postthrombotic syndrome after primary event of deep venous thrombosis 10 to 20 years ago," Thrombosis Research, vol. 101, no. 2, pp. 23-33, 2001.

[27] M. Stain, V. Schonauer, E. Minar et al., "The post-thrombotic syndrome: risk factors and impact on the course of thrombotic disease," Journal of Thrombosis and Haemostasis, vol. 3, no. 12, pp. 2671-2676, 2005.

[28] I. Lopez-Azkarreta, S. Reus, P. Marco et al., "Prospective study of the risk factors for the development of post-thrombotic syndrome after proximal deep venous thrombosis," Medicina Clinica, vol. 125, no. 1, pp. 1-4, 2005.

[29] N. A. Gooley and D. S. Sumner, "Relationship of venous reflux to the site of venous valvular incompetence: implications for venous reconstructive surgery," Journal of Vascular Surgery, vol. 7, no. 1, pp. 50-59, 1988.

[30] S. Rosfors, L. O. Lamke, E. Nordstrom, and S. Bygdeman, "Severity and location of venous valvular insufficiency: the importance of distal valve function," Acta Chirurgica Scandinavica, vol. 156, no. 10, pp. 689-694, 1990.

[31] P. S. van Bemmelen, G. Bedford, K. Beach, and D. E. Strandness Jr., "Status of the valves in the superficial and deep venous system in chronic venous disease," Surgery, vol. 109, no. 6, pp. 730-734, 1991.

[32] M. H. Meissner, M. T. Caps, B. K. Zierler et al., "Determinants of chronic venous disease after acute deep venous thrombosis," Journal of Vascular Surgery, vol. 28, no. 5, pp. 826-833, 1998.

[33] P. Prandoni, A. W. A. Lensing, and M. R. Prins, "Longterm outcomes after deep venous thrombosis of the lower extremities," Vascular Medicine, vol. 3, no. 1, pp. 57-60, 1998.

[34] A. A. Ashrani and J. A. Heit, "Incidence and cost burden of post-thrombotic syndrome," Journal of Thrombosis and Thrombolysis, vol. 28, no. 4, pp. 465-476, 2009.

[35] S. R. Kahn, "The post-thrombotic syndrome," Thrombosis Research, vol. 127, supplement 3, pp. 589-592, 2011.

[36] T. Baglin, R. Luddington, K. Brown, and C. Baglin, "Incidence of recurrent venous thromboembolism in relation to clinical and thrombophilic risk factors: prospective cohort study," The Lancet, vol. 362, no. 9383, pp. 523-526, 2003. 
[37] J. A. Heit, D. N. Mohr, M. D. Silverstein, T. M. Petterson, W. M. O'Fallon, and L. J. Melton, "Predictors of recurrence after deep vein thrombosis and pulmonary embolism: a populationbased cohort study," Archives of Internal Medicine, vol. 160, no. 6, pp. 761-768, 2000.

[38] M. T. Betancourt and M. A. Rodger, "Risk stratification for recurrent venous thromboembolism in unprovoked venous thromboembolism's patients," Acta Chirurgica Belgica, vol. 107, no. 6, pp. 636-640, 2007.

[39] N. Labropoulos, J. Jen, H. Jen, A. P. Gasparis, and A. K. Tassiopoulos, "Recurrent deep vein thrombosis: long-term incidence and natural history," Annals of Surgery, vol. 251, no. 4, pp. 749$753,2010$.

[40] M. Cushman, "Inherited risk factors for venous thrombosis," Hematology, pp. 452-457, 2005.

[41] A. Marchiori, L. Mosena, M. H. Prins, and P. Prandoni, "The risk of recurrent venousthromboembolism among heterozygous carriers of factor V-leiden orprothrombin G 20210A mutation . A systemic review of prospective studies," Hematologica, vol. 92, no. 8, pp. 1107-1110, 2007.

[42] C. Kearon, "Natural history of venous thromboembolism," Circulation, vol. 107, no. 23, supplement 1, pp. 122-130, 2003.

[43] S. Crisan, S. Vesa, C. Pestrea et al., "Chronic thrombotic scarring in patients with acute deep venous thrombosis of the lower extremities," Medical Ultrasonography, vol. 12, no. 2, pp. 114-119, 2010.

[44] M. H. Meissner, M. T. Caps, R. O. Bergelin, R. A. Manzo, and D. E. Strandness Jr., "Propagation, rethrombosis and new thrombus formation after acute deep venous thrombosis," Journal of Vascular Surgery, vol. 22, no. 5, pp. 558-567, 1995.

[45] R. J. Beyth, A. M. Cohen, and C. S. Landefeld, "Longterm outcomes of deep-vein thrombosis," Archives of Internal Medicine, vol. 155, no. 10, pp. 1031-1037, 1995.

[46] L. Spiezia, E. Campello, E. Giolo, S. Villalta, and P. Prandoni, "Thrombophilia and the risk of post-thrombotic syndrome: retrospective cohort observation," Journal of Thrombosis and Haemostasis, vol. 8, no. 1, pp. 211-213, 2010.

[47] A. Delluc, C. Gouedard, L. De Saint Martin et al., "Incidence, risk factors and skin manifestations of post-thrombotic syndrome: a four-year follow-up of patients included in the EDITH study," Revue de Medecine Interne, vol. 31, no. 11, pp. 729-734, 2010.

[48] Y. Gaber, H. J. Siemens, and W. Schmeller, "Resistance to activated protein $\mathrm{C}$ due to factor $\mathrm{V}$ Leiden mutation: high prevalence in patients with post-thrombotic leg ulcers," British Journal of Dermatology, vol. 144, no. 3, pp. 546-548, 2001.

[49] L. Spezia, D. Tormene, R. Pesavento, L. Salmaso, P. Simioni, and P. Prandoni, "Thrombophilia as a predictor of persistent residual venous thrombosis," Hematologica, vol. 93, no. 3, pp. 479-480, 2008.

[50] J. A. Gonzalez-Fajardo, M. Martin-Pedrosa, J. Castrodeza, S. Tamames, and C. Vaquero-Puerta, "Effect of the anticoagulant therapy in the incidence of post-thrombotic syndrome and recurrent thromboembolism: comparative study of enoxaparin versus coumarin," Journal of Vascular Surgery, vol. 48, no. 4, pp. 953-959, 2008. 


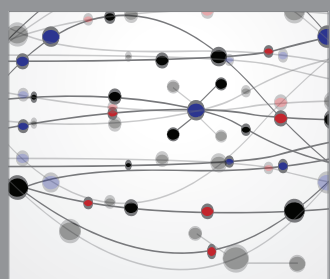

The Scientific World Journal
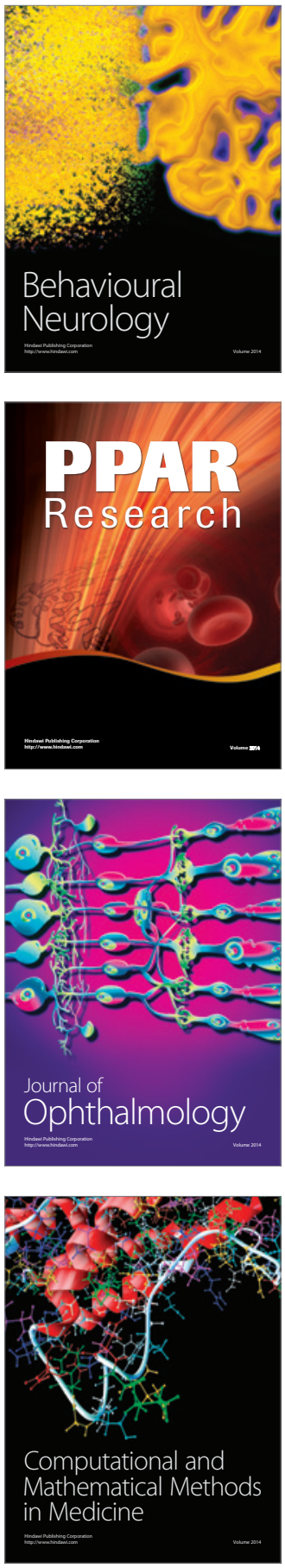

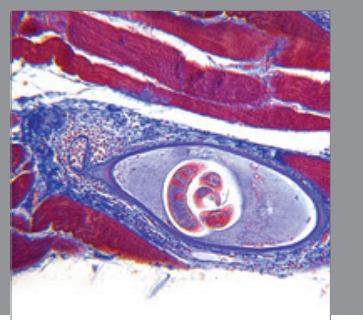

Gastroenterology

Research and Practice
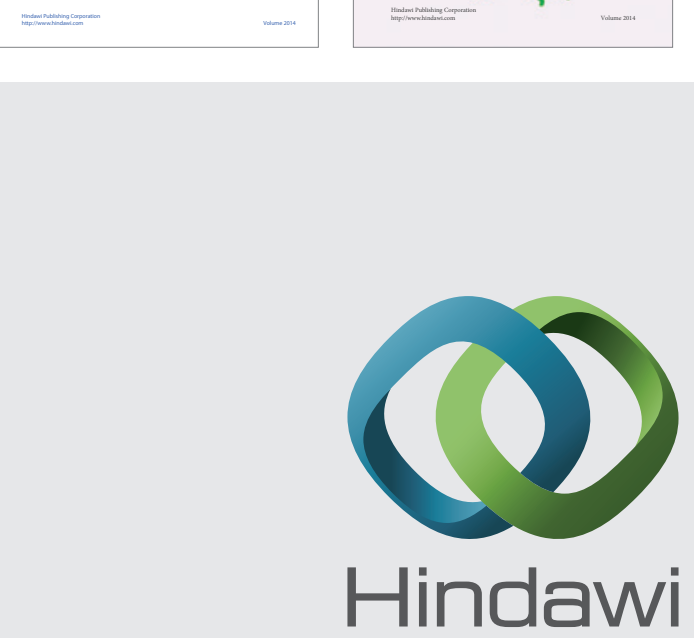

Submit your manuscripts at

http://www.hindawi.com
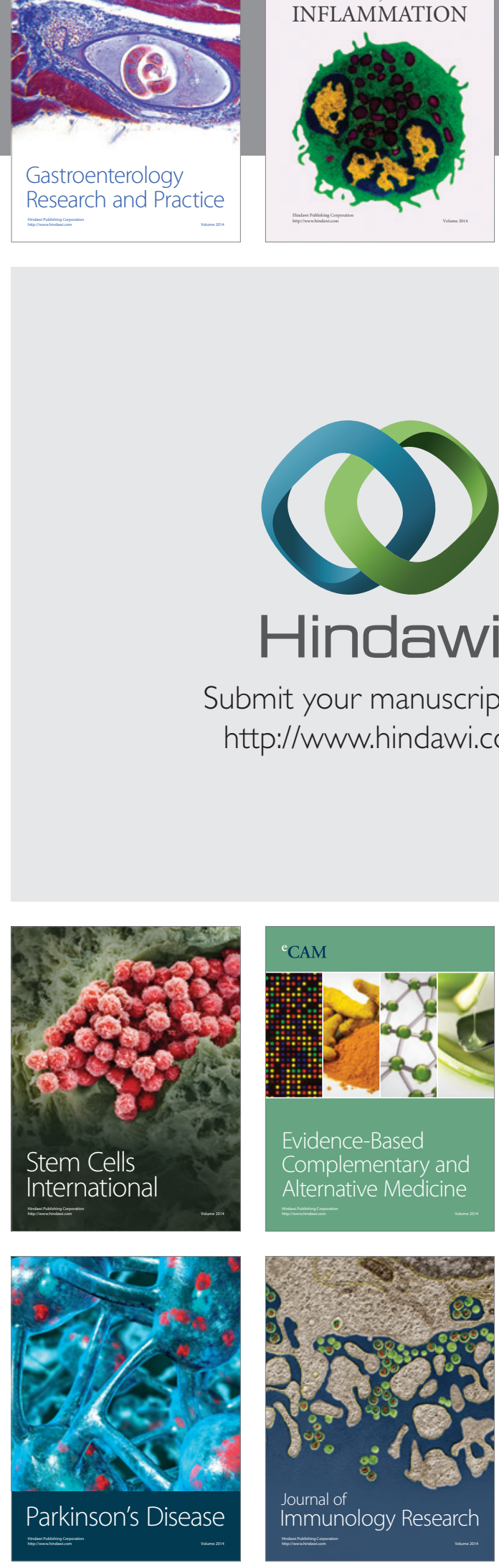

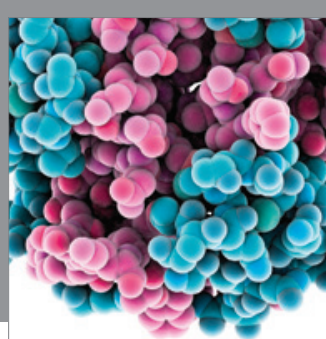

Diabetes Research
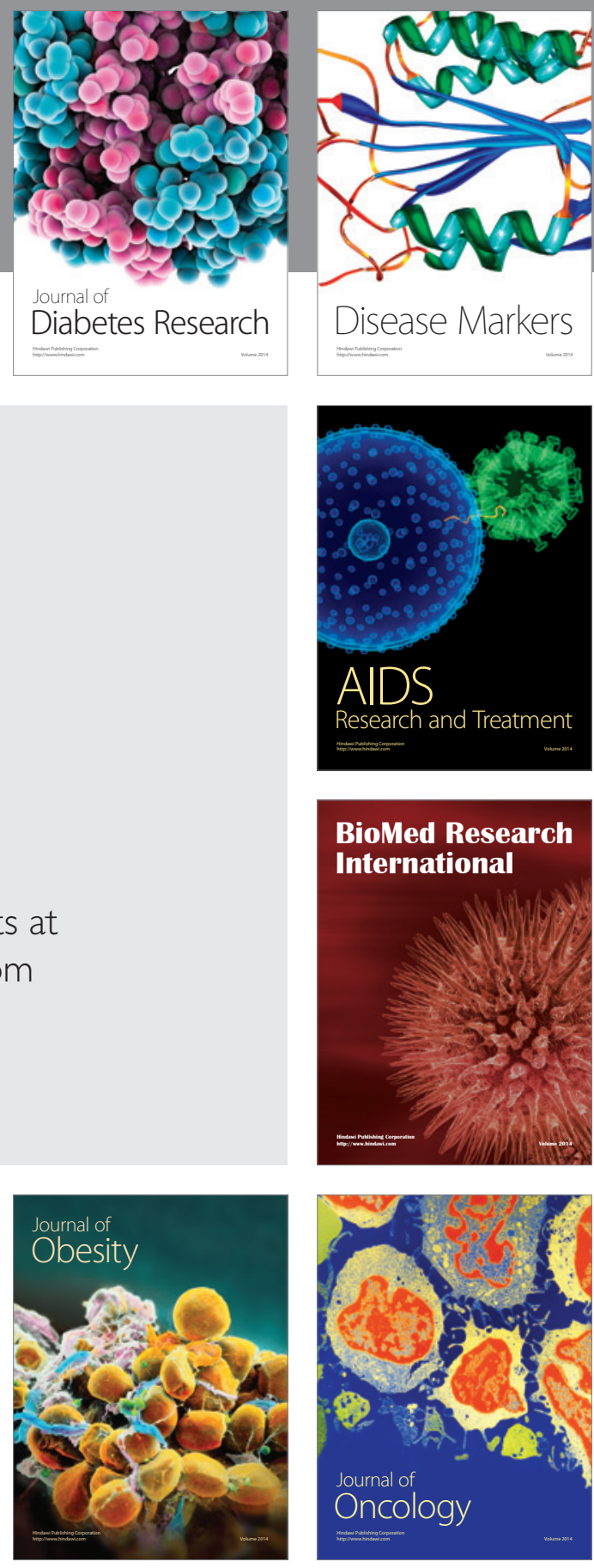

Disease Markers

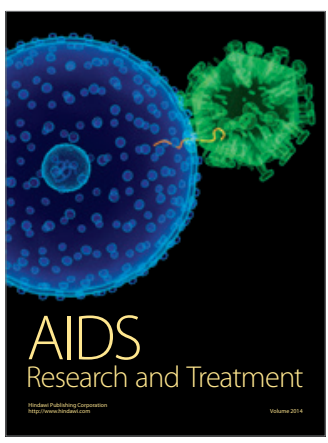

BioMed Research

International
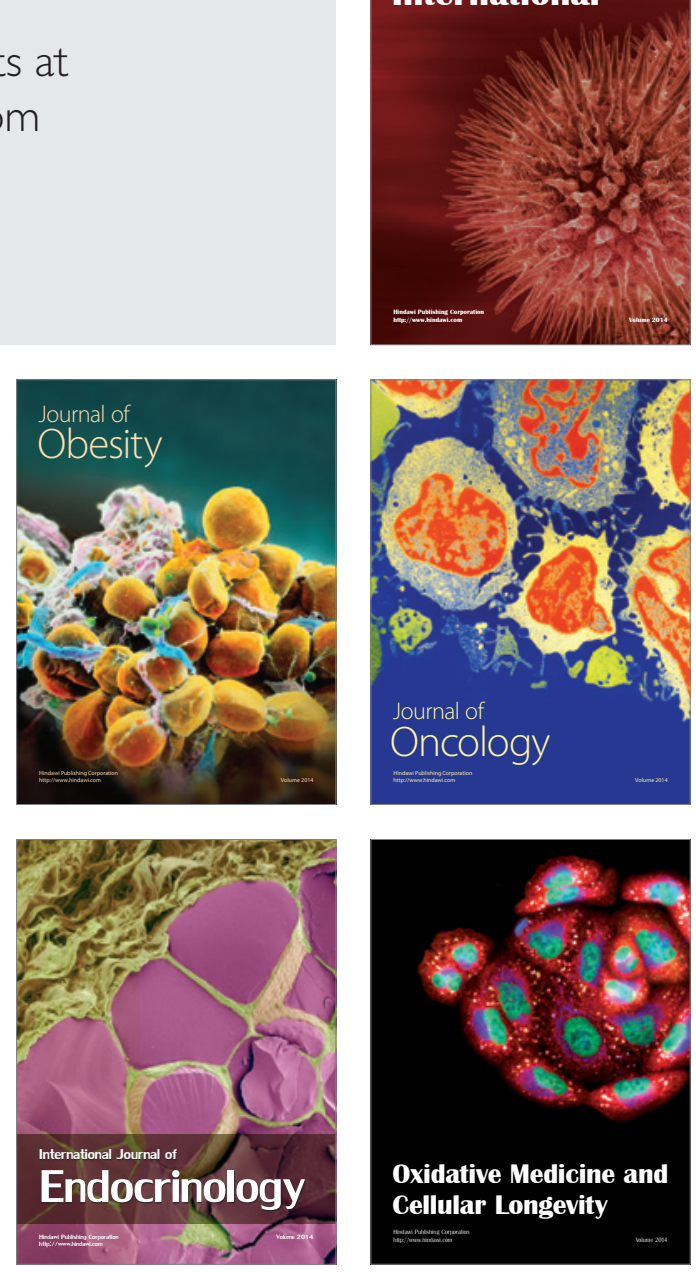